\title{
Markups in a two-country monopolistic competition model of trade with heterogeneous consumers
}

\author{
Alexander Osharin ${ }^{1 *} \mathbb{E}$, Valery Verbus ${ }^{1,2}$, Irina Bakunina ${ }^{1}$, Vera Silaeva ${ }^{1}$ and Marina Silaeva ${ }^{1}$
}

*Correspondence:
aosharin@hse.ru;
alex1486@yandex.ru
${ }^{1}$ National Research
University Higher School
of Economics, Nizhny
Novgorod 603155, Russia
Full list of author information
is available at the end of the
article

*Correspondence: aosharin@hse.ru;

${ }^{1}$ National Research

University Higher School

of Economics, Nizhny

Full list of author information article

\begin{abstract}
The paper develops a two-country monopolistic competition model of trade featuring country-specific consumer tastes. The accounting for heterogeneity in tastes is achieved by assuming different elasticities of substitution in the CES utility function for different country consumers. The proposed framework extends the canonical Krugman's approach by revealing new effects regarding markups response to consumer heterogeneity and trade liberalization. Specifically, the model predicts that, depending on the preference structure, trade liberalization may lead either to decrease or increase in the level of markups, charged by monopolistically competitive firms across destination countries.
\end{abstract}

Keywords: Heterogeneous consumers, Monopolistic competition, CES utility function, International trade, Markups

JEL Classification: F12, D43, L13

\section{Introduction}

The influence of consumer preferences on international trade patterns is among widely discussed topics in the modern economic literature (Fieler 2011; Caron et al. 2014; Di Comite et al. 2014; Simonovska 2015; Hottman et al. 2016). The interest to this issue is boosted by a large number of empirical facts that cannot be satisfactorily explained in the framework of existing models (Obstfeld and Rogoff 2000; Markusen 2013; Caron et al. 2011, 2014; Cassing and Nishioka 2015). Despite the appearing evidence on the cross-country differences in consumer tastes and demand patterns (Knight 1999; Aizenman and Brooks 2008; Atkin 2013; Auer 2010, 2017; Jakel 2019), the intra-industry trade literature until recently paid little attention to this fact. Indeed, the number of existing trade papers typically postulate identical and homothetic preferences across consumers. This assumption, which is in the center of canonical models of trade (Krugman 1980; Helpman and Krugman 1985), implies that the market demand function is the same for the same varieties across different countries as well as for different varieties within the country.

(c) The Author(s) 2020. This article is licensed under a Creative Commons Attribution 4.0 International License, which permits use, sharing, adaptation, distribution and reproduction in any medium or format, as long as you give appropriate credit to the original author(s) and the source, provide a link to the Creative Commons licence, and indicate if changes were made. The images or other third party material in this article are included in the article's Creative Commons licence, unless indicated otherwise in a credit line to the material. If material is not included in the article's Creative Commons licence and your intended use is not permitted by statutory regulation or exceeds the permitted use, you will need to obtain permission directly from the copyright holder. To view a copy of this licence, visit http://creativeco mmons.org/licenses/by/4.0/. 
In trying to extend the analysis of trade patterns, we consider a model of international trade with heterogeneous consumers whose preferences depend on their tastes. Our approach is similar to the standard Krugman's setting (Krugman 1980) with one exception: the taste parameter, which characterizes the specificity of preferences, takes different values for consumers in different countries.

The main objective of the paper is an investigation of the markup variability across markets and its response to consumer heterogeneity and trade liberalization. In accordance with the canonical approach (Krugman 1980), firm markups are the same both within and across destination countries. This result is a natural consequence of identical consumers endowed with the constant elasticity of substitution (CES) preferences. Omitting a consumer homogeneity assumption enables one to reveal variability of markups across countries, which is observed empirically (Syverson 2007; De Loecker and Warzynski 2012; Bellone et al. 2014; Di Comite et al. 2014; Simonovska 2015; Feenstra and Weinstein 2017), but cannot be captured by models of trade featuring identical and homothetic preferences. Contrary to the canonical approach, our paper shows that markups may depend not only on the parameters of consumer preferences, the relative size of countries and transportation costs, but also on the ratio of mill prices, the ratio of wages, and the ratio of number of firms in trading countries.

It is worth noting that the recent research papers on trade, in trying to determine factors related to markups, has thoroughly investigated firm pricing behavior under a wide range of assumptions. One of the first attempts to structurally estimate the impact of globalization on markups in a monopolistic competition setting with non-CES preferences was taken by Feenstra and Weinstein (2010). To achieve this goal, the authors utilized the translog utility function that allows for endogenous markups. Structural estimations of the impact of globalization on markups, carried out in this paper, showed the existence of a pro-competitive effect in firm pricing behavior: alongside the increase of U.S. imports between 1992 and 2005 markups went down, while product variety and welfare went up. Similar results were obtained by Chen et al. (2009), who used disaggregated data for EU manufacturing over the period 1989-1999 and found short-run evidence that trade openness exerts a pro-competitive effect, with prices and markups falling and productivity rising. They also found (albeit weaker) support that the long-run effects are more ambiguous and may even be anti-competitive. An investigation into the impacts of trade liberalization and market size on markups was carried out in Behrens et al. (2014) by using a full-fledged general equilibrium model with heterogeneous firms. Taking their model to the data, the authors derived a gravity equation under the general equilibrium constraints generated by the model, and structurally estimated it using a dataset on interregional trade flows between U.S. states and Canadian provinces. Consistent with the results listed above, the authors also quantify the pro-competitive effects of trade integration.

Although the pro-competitive behavior of the firm-level markups are confirmed elsewhere (Levinsohn 1993; Krishna and Mitra 1998; Lundin 2004; Noria 2013), it should be noted that currently there is no general agreement on this point. An example of this is Fan et al. (2015) who used Chinese firm-product data to show that trade liberalization via input tariff reductions induced an incumbent importer/exporter to increase product markups, and Meinen (2016), who presented some evidence on raising Danish firm-level 
markups in response to Chinese imports. These findings, as it seems, call for a reconsideration of the established imports-as-market-discipline hypothesis, which states that a higher volume of imports intensifies competition and hence decreases the market power of a firm. An ambiguous prediction of the openness to trade influence upon the level of markups was also reported by Thompson (2002), who estimated price-marginal cost markups for Canadian manufacturing industries during the 1970s in order to assess the impact of import competition on domestic market power and found no consistent evidence that imports reduced the markups of Canadian firms during that period.

What is interesting is that our model also demonstrates mixed predictions towards this issue. In contrast to what is obtained in most of the listed publications, the final conclusion on markup behavior in our setting crucially depends upon the relative size of the countries engaged in trade and the relationship between consumers' taste parameters across destinations. It is shown, for example, that trade liberalization reduces markups in a larger (smaller) country having smaller (larger) value of the taste parameter and increases markups in a smaller (larger) country having larger (smaller) value of the taste parameter.

The paper proceeds as follows. In Sect. 2, we formulate our baseline trade model of the two countries populated by consumers differing in their preferences. In Sect. 3, we present the main results obtained (numerically) by comparative statics analysis. Section 4 concludes.

\section{Model descriptions}

Consider the world economy consisting of two countries $A$ and $B$, each producing differentiated varieties with increasing returns to scale and operating in a monopolistically competitive setting. Let $L_{r}$ is the number of consumers/workers in country $r(r=A, B)$, each of whom inelastically supplies one unit of labor. The labor is assumed to be the only factor of production which is internationally immobile. Denote by $L=L_{A}+L_{B}$ the world population, and by $\theta=L_{A} / L$ the share of country $A$ residents in the total population of the world. In what follows, country $A$ is considered a home country, and country $B$ is a foreign country.

Assume further that the preferences of consumers residing in country $r$ are identical and can be represented by CES utility function:

$$
U_{r}=\left(\sum_{i=1}^{N_{r}}\left(x_{\mathrm{rr}}(i)\right)^{\left(\sigma_{r}-1\right) / \sigma_{r}}+\sum_{j=1}^{N_{s}}\left(x_{\mathrm{sr}}(j)\right)^{\left(\sigma_{r}-1\right) / \sigma_{r}}\right)^{\sigma_{r} /\left(\sigma_{r}-1\right)},
$$

where $x_{\mathrm{rr}}(i)$ is the quantity of $i$ th variety produced and consumed in country $r, x_{\mathrm{sr}}(j)$ is the quantity of $j$ th variety produced in country $s$ and consumed in country $r ; N_{r}$ is the number of varieties produced in country $r, N_{s}$ is the number of varieties, produced in country $s ; \sigma_{r}>1$ is the taste parameter of consumers in country $r$.

Although preferences of consumers in each country are the same, they may differ across destinations. This means that consumers across different countries are assumed 
to be heterogeneous in tastes. ${ }^{1}$ This heterogeneity is achieved by using different $\sigma_{r}$ values in utility function of different country consumers (in general, $\sigma_{r} \neq \sigma_{s}, r \neq s$ ). Our goal here is to analyze how the differences in consumer preferences across destinations and trade liberalization affect the behavior of the firm-level markups.

According to (1), imported goods contribute to the consumer's utility equally to the domestically produced goods (provided the quantity of the goods is the same). However, consumption of imported goods entails additional costs arising from the costs of transportation, which are assumed to be an "iceberg-type". This means that if a good is produced in country $A$, the transportation costs of quantity $q$ of this good from $A$ to $B$ are actually accounted assuming that $\tau \mathrm{q}$ units of this good must be sent from one location to another, where $\tau \geq 1$ is a transportation costs index (the limiting case $\tau=1$ corresponds to zero transportation costs).

Suppose now that firms follow a mill pricing policy. If $p_{r}(i)$ is a mill price of variety $i$ in country $r$, then its delivered price in country $s(s \neq r)$ including transportation costs is

$$
p_{\mathrm{rs}}(i)=\tau p_{r}(i) \geq p_{r}(i) .
$$

Assuming that each country consumers are also employees of the firms located in this country, the budget constraint of a consumer in country $r$ can be written as follows:

$$
\sum_{i=1}^{N_{r}} p_{r}(i) x_{\mathrm{rr}}(i)+\sum_{j=1}^{N_{s}} \tau p_{s}(j) x_{\mathrm{sr}}(j)=w_{r},
$$

where $w_{r}$ is an income of the consumer equal to her/his wage.

\subsection{Consumer problem}

Solving the consumer problem, one can find an individual demand for variety $i$, produced and consumed in country $r$ :

$$
x_{\mathrm{rr}}(i)=\left(\frac{p_{r}(i)}{P_{r}}\right)^{-\sigma_{r}} \frac{w_{r}}{P_{r}} .
$$

Because a good is produced and marketed in the same country, we do not include the transportation costs. The demand of the same consumers for $j$ th variety, shipped from country $s$, is

$$
x_{\mathrm{sr}}(j)=\left(\frac{\tau p_{s}(j)}{P_{r}}\right)^{-\sigma_{r}} \frac{w_{r}}{P_{r}} .
$$

In this case, we account for transportation costs as the locations of production and consumption are different. This is a "remote demand" with transportation costs accounted by $\tau$. As can be seen from (4) and (5), at the same mill price the consumption of an imported variety is lower than the consumption of a domestic variety by a factor of

\footnotetext{
1 The possibility of this is advocated by (Di Comite et al. 2014), where an illustrative example of different types of beers is given showing that demand for Heineken in one country can differ from the demand for Budweiser in another one where both beers are also sold.
} 
$\tau^{-\sigma_{r}}$ because its delivered price is higher. The price index $P_{r}$ appearing in the individual demand functions equals to

$$
P_{r}=\left(\sum_{i=1}^{N_{r}}\left(p_{r}(i)\right)^{-\left(\sigma_{r}-1\right)}+\sum_{j=1}^{N_{s}}\left(\tau p_{s}(j)\right)^{-\left(\sigma_{r}-1\right)}\right)^{-1 /\left(\sigma_{r}-1\right)} .
$$

Notice that this index turns out to be a country specific due to the difference in taste parameters $\sigma_{r}$ and $\sigma_{s}$ across destinations.

\subsection{Producer problem}

Firms in both countries have access to the same production technology with increasing returns to scale. The total cost needed to produce $q_{r}(i)$ units of variety $i$ in country $r$ $(r=A, B)$ is given by

$$
C_{r}(i)=\left(m q_{r}(i)+f\right) w_{r}
$$

where $f>0$ and $m>0$ being the fixed and the marginal costs which firms incur in terms of labor. Taking (7) into account, the profit of a firm located in country $r$ can be written as

$$
\pi_{r}(i)=\left(p_{r}(i)-m w_{r}\right) q_{r}(i)-f w_{r}
$$

where market demand function $q_{r}(i)$ for variety $i$ consists of two components:

$$
q_{r}(i)=q_{\mathrm{rr}}(i)+\tau q_{\mathrm{rs}}(i) .
$$

The first component is the market demand of domestic residents:

$$
q_{\mathrm{rr}}(i)=\left(\frac{p_{r}(i)}{P_{r}}\right)^{-\sigma_{r}} \frac{Y_{r}}{P_{r}}
$$

where $Y_{r}=L_{r} w_{r}$ is the aggregate income of consumers in home country. The second one is the "remote" market demand of foreigners:

$$
q_{\mathrm{rs}}(i)=\left(\frac{\tau p_{r}(i)}{P_{s}}\right)^{-\sigma_{s}} \frac{Y_{s}}{P_{s}}
$$

where $Y_{s}=L_{s} w_{s}$ is the aggregate income of consumers in foreign country.

Notice that the market demand components (10) and (11) for the same variety may differ across destination countries. Both of the components are isoelastic, but elasticity of the market demand, shaped by domestic consumers (10), distinguishes, in general, from the elasticity of the market demand (11) shaped by foreigners. This difference is due to possible difference in consumers' tastes between the two countries.

Unlike the individual demands $(4,5)$ and the market demand components $(10,11)$, the total market demand function (9) is not isoelastic because the taste parameter $\sigma_{r}$ varies across trading countries. As a consequence, the market demand faced by any firm (either at home or abroad) crucially depends on the relationship between the values of the taste parameters $\sigma_{r}$ and $\sigma_{s}$. In the limiting case, where consumers share the same preferences 
with $\sigma_{r}=\sigma_{s}=\sigma$, the market demand is isoelastic so that the heterogeneity of consumers is ignored and has no impact on the patterns of trade.

\subsubsection{Short-run equilibrium}

Substituting market demand function $q_{r}(i)$ into the profit equation (8) and maximizing the resulting profit with respect to prices (for a fixed number of firms and a fixed wage level in each of the two countries), we obtain the following system of equations for mill prices $p_{A}(i)$ and $p_{B}(j)$ :

$$
\left\{\begin{array}{l}
p_{A}(i)=\frac{\bar{\varepsilon}_{A}(i)}{\bar{\varepsilon}_{A}(i)-1} m w_{A} \\
p_{B}(j)=\frac{\bar{\varepsilon}_{B}(j)}{\bar{\varepsilon}_{B}(j)-1} m w_{B}
\end{array}\right.
$$

where $i=\overline{1, N_{A}}, j=\overline{1, N_{B}}, \bar{\varepsilon}_{A}(i) \equiv-\left(p_{A}(i) / q_{A}(i)\right)\left(\partial q_{A}(i) / \partial p_{A}(i)\right)$ and $\bar{\varepsilon}_{B}(j) \equiv-\left(p_{B}(j) /\right.$ $\left.q_{B}(j)\right)\left(\partial q_{B}(j) / \partial p_{B}(j)\right)$ are aggregate elasticities of the market demand for $i$ th and $j$ th varieties, correspondingly, produced by firms in countries $A$ and $B$ (see Appendix for details). This system contains $N=N_{A}+N_{B}$ equations and can be solved numerically.

Assuming a symmetric equilibrium with the same prices for varieties produced in each of the two countries, $p_{A}(i)=p_{A}, p_{B}(j)=p_{B}$, we reduce (12) to the system of two equations for two unknowns $\left(p_{A}\right.$ and $\left.p_{B}\right)$ :

$$
\left\{\begin{array}{l}
p_{A}=\frac{\bar{\varepsilon}_{A}}{\bar{\varepsilon}_{A}-1} m w_{A} \\
p_{B}=\frac{\bar{\varepsilon}_{B}}{\bar{\varepsilon}_{B}-1} m w_{B}
\end{array}\right.
$$

Price elasticities of the market demand $\bar{\varepsilon}_{A}$ and $\bar{\varepsilon}_{B}$, appearing in (13), can be written as the weighted averages of the taste parameters $\sigma_{A}, \sigma_{B}$ (see Appendix):

$$
\left\{\begin{array}{l}
\bar{\varepsilon}_{A}=\alpha \sigma_{A}+(1-\alpha) \sigma_{B} \\
\bar{\varepsilon}_{B}=\beta \sigma_{B}+(1-\beta) \sigma_{A}
\end{array}\right.
$$

which is reasonable as long as the market demand for a good produced in any country is shaped by both domestic and foreign consumers. In this representation, coefficients $\alpha$ and $\beta$ depend on the ratios $\tilde{p} \equiv p_{A} / p_{B}, \tilde{w} \equiv w_{A} / w_{B}, \tilde{N} \equiv N_{A} / N_{B}$, taste parameters $\sigma_{A}$, $\sigma_{B}$, transportation costs $\tau$ and the relative size of trading countries $\theta$. This dependence reads as follows (see Appendix for details):

$$
\left\{\begin{array}{l}
\alpha=\frac{\gamma a}{\gamma a+(1-\gamma)(1-b)} \\
\beta=\frac{(1-\gamma) b}{(1-\gamma) b+\gamma(1-a)}
\end{array}\right.
$$

where $\gamma=(\theta \tilde{w}) /(1+\theta(\tilde{w}-1)), \quad a=1 /\left(1+\tilde{N}^{-1}(\tilde{p} / \tau)^{\sigma_{A}-1}\right), \quad b=1 /\left(1+\tilde{N}^{-1}\right.$ $\left.(\tilde{p} / \tau)^{\sigma_{B}-1}\right)$. Thus, (13) is a self-consistent system of nonlinear algebraic equations for short-run equilibrium prices. Given the values of the exogenous parameters $\left(\tilde{w}, \tilde{N}, \sigma_{A}, \sigma_{B}, \theta, \tau\right)$, one can solve this system using numerical methods. 
In the limiting case of the two countries having the same taste parameters of consumers, the equilibrium prices (13) are reduced to prices appearing in the canonical model of trade (Krugman 1980). Indeed, if $\sigma_{A}=\sigma_{B}=\sigma$, then $\bar{\varepsilon}_{A}=\bar{\varepsilon}_{B}=\sigma$ and

$$
\left\{\begin{array}{l}
p_{A}=\frac{\sigma}{\sigma-1} m w_{A} \\
p_{B}=\frac{\sigma}{\sigma-1} m w_{B}
\end{array} .\right.
$$

These prices differ only because of the differences in wages of consumers/workers in the two countries.

Now define firm markups in each of the two trading countries:

$$
\left\{\begin{array}{c}
\bar{\mu}_{A} \equiv \frac{p_{A}-m w_{A}}{p_{A}}=\frac{1}{\bar{\varepsilon}_{A}} \\
\bar{\mu}_{B} \equiv \frac{p_{B}-m w_{B}}{p_{B}}=\frac{1}{\bar{\varepsilon}_{B}} .
\end{array}\right.
$$

These markups are inversely proportional to the elasticities of the market demand for any variety in countries $A$ and $B$, correspondingly, thus making it possible for firms located in the country with relatively lower aggregate elasticity to charge higher markups. In the limiting case with the same taste parameters across consumers and countries, the markups (17) turns out to be identical and constant:

$$
\bar{\mu}_{A}=\bar{\mu}_{B} \equiv \mu=1 / \sigma
$$

exactly like in the canonical model of trade (Krugman 1980).

The constancy of markups, which stems from the canonical model of trade, sharply contrasts with our findings. As follows from the system of Eq. (13), markups in our model are variable and depend not only on the parameters of consumer preferences, but also on price, wage, and number of firm ratios, as well as on the relative size of countries and transportation costs. This is more in line with empirical studies showing that firm markups are not constant and differ for different countries (Syverson 2007; Feenstra and Weinstein 2010; De Loecker and Warzynski 2012; Bellone et al. 2014; Di Comite et al. 2014). To create a detailed understanding of the behavior of firmproduct markups in our model, we turn to the analysis of the long-run equilibrium.

\subsubsection{Long-run equilibrium}

Mill prices for different types of goods in countries $A$ and $B$, given in the previous section, were obtained under the assumption of an exogenously defined distribution of wages and number of firms in each of the two countries. To find the general equilibrium of the model, we have to make these parameters endogenous. This can be done by assuming free entry and exit of firms on the market, which is equivalent to zero profit condition in both countries, and taking into account the balance of payments equilibrium. As a result, we get a system of nonlinear algebraic equations for three endogenous parameters $\tilde{p}, \tilde{w}, \tilde{N}$, which can be written as follows: 


$$
\left\{\begin{array}{l}
\tilde{p}=\xi \tilde{w} \\
\tilde{N}=\zeta(\theta /(1-\theta)) \\
(1-\gamma)(1-b)=\gamma(1-a)
\end{array},\right.
$$

where coefficients $\xi$ and $\zeta$ denote combinations of elasticities of the market demands: $\xi \equiv\left(\bar{\varepsilon}_{A}\left(\bar{\varepsilon}_{B}-1\right)\right) /\left(\bar{\varepsilon}_{B}\left(\bar{\varepsilon}_{A}-1\right)\right), \zeta \equiv \bar{\varepsilon}_{A} / \bar{\varepsilon}_{B}$.

Taking into account the balance of payments (which is the third equation in (19)), $\alpha$ and $\beta$ coefficients appearing in (14) are simplified to $\alpha=a$ and $\beta=b$ (see Appendix for proof), which makes it possible to rewrite the market demand elasticities as:

$$
\left\{\begin{array}{l}
\bar{\varepsilon}_{A}=a \sigma_{A}+(1-a) \sigma_{B} \\
\bar{\varepsilon}_{B}=b \sigma_{B}+(1-b) \sigma_{A}
\end{array} .\right.
$$

In view of $a$ and $b$ expressions, given previously, note that these coefficients depend exclusively on the tastes parameters of the domestic consumers, and do not depend on the tastes parameters of the foreigners: $a=a\left(\sigma_{A}\right), b=b\left(\sigma_{B}\right)$. Given exogenous parameters of the model, the ratios $\tilde{p}, \tilde{w}$, and $\tilde{N}$ can be found by solving numerically the system of Eq. (19). By substituting this solution into (20) and (17), we will find the markups in each of the two trading countries. In the autarky case, where $\tau \rightarrow \infty$, we have $\bar{\varepsilon}_{A}=\sigma_{A}, \bar{\varepsilon}_{B}=\sigma_{B}$, and hence $\bar{\mu}_{A}=1 / \sigma_{A}, \bar{\mu}_{B}=1 / \sigma_{B}$, which means that price elasticities of the market demand for domestic varieties and corresponding markups of incumbent firms are determined by the taste parameters of domestic consumers, which is expectable.

\section{Results}

The analysis of the general equilibrium of the model allows for interesting predictions regarding the behavior of markups. Note that, in accordance with (19), the level of markups in each of the two countries depends on three endogenous $(\tilde{p}, \tilde{w}, \tilde{N})$ and four exogenous $\left(\sigma_{A}, \sigma_{B}, \theta, \tau\right)$ parameters of the model. This result contrasts with the case of homogeneous preferences, where firm markups in the two trading countries are the same and constant. Indeed, in accordance with (18), the level of markups in the canonical model of trade depends on a single parameter $\sigma$ which is the same across destinations. In our model, we have variable markups, which reaction to trade liberalization can be found by varying transportation $\operatorname{costs} \tau$ at given values of the remaining exogenous parameters.

Figures 1 and 2 show the dependence of markups in countries $A$ and $B$ on the degree of trade liberalization, measured by inverse of the transportation costs index $1 / \tau$, for the case when the relative size of country $A$ is larger than the relative size of country $B(\theta=0.8)$. Figure 1 demonstrates the case where $\sigma_{A}<\sigma_{B}\left(\sigma_{A}=2, \sigma_{B}=3\right)$, Fig. 2 demonstrates the case where $\sigma_{A}>\sigma_{B}\left(\sigma_{A}=3, \sigma_{B}=2\right)$.

As can be seen from these figures, trade liberalization reduces markups in the country having less elastic demand, shaped by domestic consumers (i.e., lower $\sigma_{r}$ ) and increases markups in the country with more elastic home-market demand (i.e., higher $\left.\sigma_{r}\right)$. Changes of markups, either decrease of increase, are stronger in country that has a relatively smaller size (in this case, country $B$ ). 


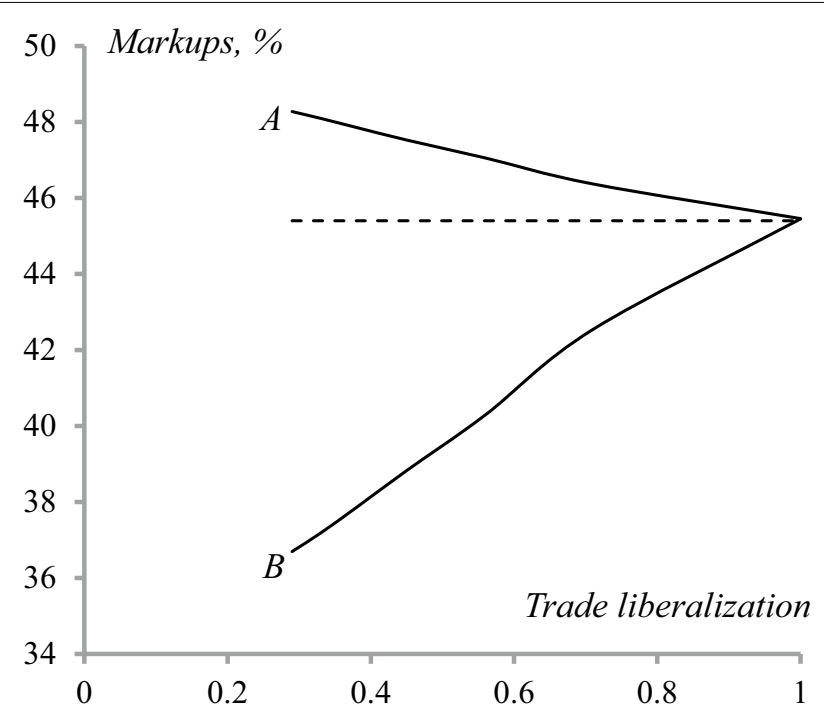

Fig. 1 Markups in trading countries vs trade liberalization $\left(\sigma_{A}<\sigma_{B}\right)$

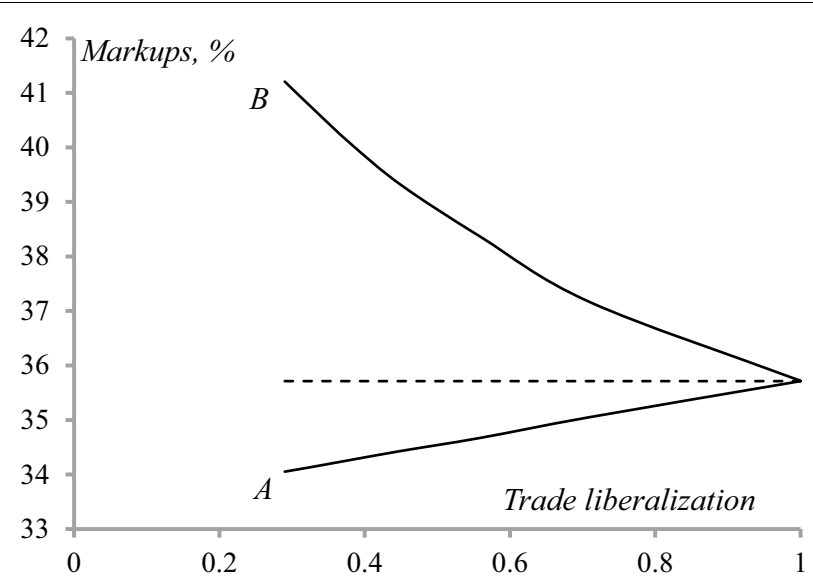

Fig. 2 Markups in trading countries vs trade liberalization $\left(\sigma_{A}>\sigma_{B}\right)$

This result can be explained qualitatively by analyzing elasticities of the market demand for varieties in either of the two countries, $\bar{\varepsilon}_{A}$ and $\bar{\varepsilon}_{B}$, which determine firm markup values, as functions of the trade liberalization parameter $1 / \tau$.

The lower the transportation costs (and higher the trade liberalization parameter), the greater is the contribution of foreign consumers into the elasticity of the market demand for domestic goods. If preferences of domestic residents are characterized by a lower value of the taste parameter (as in Fig. 1), then the increasing foreign consumer contribution will lead to an increase in the elasticity of the market demand for domestic products. This will reduce the market power of domestic firms and decrease markups for local goods.

If domestic consumers shape demand which is characterized by a relatively higher value of the taste parameter compared to the foreign one (Fig. 2), then we will have 
an opposite effect. A liberal shift in trade policy in this case will lead to an increase in markups charged by domestic firms.

The empirical studies of the trade liberalization impact on the markups in the monopolistic competition setting were carried out in a number of contributions. Most of them (see references listed above) conclude that markups are negatively related to the openness of trade. Nevertheless, there exit a few exceptions evidencing a positive reaction of firm markups on trade liberalization. The examples are Fan et al. (2015) and Meinen (2016), where an evidence on raising firm-level markups in response to imports are documented. An ambiguous prediction of the openness to trade impact upon the level of markups was also reported by Thompson (2002). Our model offers a new additional channel through which trade liberalization can exert influence on the markup levels providing either decrease or increase in their values. This can be due to the difference in country-specific tastes for the same good demonstrated by domestic and foreign consumers.

\section{Conclusion}

This paper develops a two-country trade model of monopolistic competition featuring consumers' heterogeneity across destinations, which is accounted by assuming different elasticities of substitution in the CES utility function for different country consumers. The model generates a set of new predictions regarding behavior of firmproduct markups in trading countries as functions of the degree of trade liberalization. It shows that markups in the industrial sectors depend on three endogenous parameters, which are the price, wage and number of firm ratios in trading countries, and four exogenous parameters, which are the two country-specific consumer taste parameters, transportation costs and the relative size of trading countries. Depending on the relationship between tastes of consumers in different countries, trade liberalization may provide either decrease or increase in the level of markups. This finding distinguishes our model from the canonical one, in which markups in the industrial sectors of trading countries are constant. It is worth noting that we do not consider taste heterogeneity as being the only possible factor influencing product-firm markups variation across destination countries. All that we claim is that country-specific tastes of consumers can serve as an additional potential source of firm markups variation accompanying trade liberalization.

Acknowledgements

The authors acknowledge the financial support from RFBR fund Grant \# 17-06-00572.

Authors' contributions

All the authors in this research paper have their own contribution. All authors read and approved the final manuscript.

Funding

This is an original research work supported by RFBR fund Grant \# 17-06-00572.

Availability of data and materials

The data are available upon request.

Competing interests

The authors declare that they have no competing interests. Author's names are aligned according to their contribution.

Author details

${ }^{1}$ National Research University Higher School of Economics, Nizhny Novgorod 603155, Russia. ${ }^{2}$ Institute for Physics

of Microstructures of the RAS, Nizhny Novgorod 603950, Russia. 


\section{Appendix}

\section{Short-run equilibrium equations}

Applying the first-order condition to profit function (8) gives the following equation:

$$
\frac{\partial \pi_{A}(i)}{\partial p_{A}(i)}=\frac{\partial}{\partial p_{A}(i)}\left(p_{A}(i) q_{A}(i)-m w_{A} q_{A}(i)-f w_{A}\right)=q_{A}(i)+p_{A}(i) \frac{\partial q_{A}(i)}{\partial p_{A}(i)}-m w_{A} \frac{\partial q_{A}(i)}{\partial p_{A}(i)}=0 .
$$

Taking into account that the elasticity of the market demand for $i$ th variety in country $A$ is given by $\bar{\varepsilon}_{A}(i) \equiv-\left(p_{A}(i) / q_{A}(i)\right)\left(\partial q_{A}(i) / \partial p_{A}(i)\right)$, the first-order condition results in $p_{A}(i)=\left[\bar{\varepsilon}_{A}(i) /\left(\bar{\varepsilon}_{A}(i)-1\right)\right] m w_{A}$. Similar equation can be found from differentiating the profit function of the $j$ th firm in country $B$. Combining these two equations, we will have the system (12) given in the text.

\section{Elasticities of the market demand in the symmetric short-run equilibrium}

In the case of symmetric equilibrium with identical prices for varieties $\left(p_{A}(i)=p_{A}, \quad i=1,2, \ldots, N_{A}\right.$ and $\left.p_{B}(j)=p_{B}, j=1,2, \ldots, N_{B}\right)$, the elasticities of the market demand are reduced to the following expressions:

$$
\left\{\begin{array}{rl}
\bar{\varepsilon}_{A} & =\frac{A A \cdot \sigma_{A}+A B \cdot \sigma_{B}}{A A+A B} \\
\bar{\varepsilon}_{B} & \equiv \frac{B B \cdot \sigma_{B}+B A \cdot \sigma_{A}}{B B+B A}
\end{array},\right.
$$

where $\quad A A \equiv \frac{\left(p_{A}\right)^{1-\sigma_{A}}}{N_{A}\left(p_{A}\right)^{1-\sigma_{A}}+N_{B}\left(\tau p_{B}\right)^{1-\sigma_{A}}} Y_{A}, \quad A B \equiv \frac{\left(\tau p_{A}\right)^{1-\sigma_{B}}}{N_{B}\left(p_{B}\right)^{1-\sigma_{B}}+N_{A}\left(\tau p_{A}\right)^{1-\sigma_{B}}} Y_{B}, \quad B B \equiv$ $\frac{\left(p_{B}\right)^{1-\sigma_{B}}}{N_{B}\left(p_{B}\right)^{1-\sigma_{B}}+N_{A}\left(\tau p_{A}\right)^{1-\sigma_{B}}} Y_{B}$, and $B A=\frac{\left(\tau p_{B}\right)^{1-\sigma_{A}}}{N_{A}\left(p_{A}\right)^{1-\sigma_{A}}+N_{B}\left(\tau p_{B}\right)^{1-\sigma_{A}}} Y_{A}$. Denoting the ratio of prices as $\tilde{p} \equiv p_{A} / p_{B}$, the ratio of firm numbers as $\tilde{N} \equiv N_{A} / N_{B}$, the ratio of wages as $\tilde{w} \equiv w_{A} / w_{B}$ and denoting the share of total consumer incomes of the country $A$ in the total income of the global economy as $Y_{A} / Y \equiv \gamma=(\theta \tilde{w}) /(1+\theta(\tilde{w}-1))$, the coefficients $A A, A B, B B, B A$ can be written as

$$
\left\{\begin{array}{l}
A A=\frac{\gamma}{1+\tilde{N}^{-1}(\tilde{p} / \tau)^{\sigma_{A}-1}} \\
A B=\frac{1-\gamma}{1+\tilde{N}^{-1}(\tau \tilde{p})^{\sigma_{B}-1}} \\
B B=\frac{1-\gamma}{1+\tilde{N}(\tau \tilde{p})^{-\left(\sigma_{B}-1\right)}} \\
B A=\frac{\gamma}{1+\tilde{N}(\tilde{p} / \tau)^{-\left(\sigma_{A}-1\right)}}
\end{array}\right.
$$

Denoting further $a=1 /\left(1+\tilde{N}^{-1}(\tilde{p} / \tau)^{\sigma_{A}-1}\right), b=1 /\left(1+\tilde{N}(\tau \tilde{p})^{-\left(\sigma_{B}-1\right)}\right)$, the price elasticities of the market demand can be represented in the form (14) given in the text.

\section{Simplification of the $\alpha$ and $\beta$ coefficients in the long-run equilibrium}

Let us use the trade balance equation $(1-\gamma)(1-b)=\gamma(1-a)$ from (19) to simplify the expressions for the coefficients $\alpha$ and $\beta$. To this end, rewrite the expression that appears in the denominator of the coefficient $\alpha$ as follows: 


$$
\gamma a+(1-\gamma)(1-b)=\gamma a+\gamma(1-a)=\gamma a+\gamma-\gamma a=\gamma
$$

\section{This gives}

$$
\alpha=\frac{\gamma a}{\gamma a+(1-\gamma)(1-b)}=\frac{\gamma a}{\gamma}=a .
$$

The coefficient $\beta$ can be simplified analogously. As a result, we will get $\alpha=a$ and $\beta=b$.

Received: 30 June 2019 Revised: 30 June 2019 Accepted: 7 January 2020

Published online: 10 February 2020

\section{References}

Aizenman J, Brooks E (2008) Globalization and taste convergence: the cases of wine and beer. Rev Int Econ 16(2):217-233 Atkin DG (2013) Trade, tastes and nutrition in India. Am Econ Rev 103(5):1629-1663

Auer R (2010) Consumer heterogeneity and the impact of trade liberalization: how representative is the representative agent framework? Swiss National Bank Working Papers WP-2010 (13). pp 1-35

Auer RA (2017) Product heterogeneity, cross-country taste differences, and the growth of world trade. Eur Econ Rev 100:1-27 Behrens K, Mion G, Murata Y, Sudekum J (2014) Trade, wages, and productivity. Int Econ Rev 55(4):1305-1348

Bellone F, Musso P, Nesta L, Warzynski F (2014) International trade and firm-level markups when location and quality matter. GREDEG WP No. 2014-37

Caron JJ, Fally T, Markusen JR (2011) Skill premium and trade puzzles: a solution linking production and preferences. NBER Working Paper No. 18131

Caron JJ, Fally T, Markusen JR (2014) International trade puzzles: a solution linking production and preferences. Q J Econ 129(3):1501-1552

Cassing J, Nishioka S (2015) Per capita income and the mystery of missing trade. Rev Int Econ 23(3):606-619

Chen N, Imbs J, Scott A (2009) The dynamics of trade and competition. J Int Econ 77:50-62

De Loecker J, Warzynski F (2012) Markups and firm-level export status. Am Econ Rev 102(6):2437-2471

Di Comite F, Thisse J-F, Vandenbussche H (2014) Verti-zontal differentiation in export markets. J Int Econ 93:50-66

Fan H, Li YA, Luong TA (2015) Input-trade liberalization and markups. HKUST Working paper No. 2015-26

Feenstra RC, Weinstein DE (2010) Globalization, markups and US welfare. NBER Working Paper No. 15749

Feenstra RC, Weinstein DE (2017) Globalization, markups, and US welfare. J Pol Econ 125(4):1040-1074

Fieler AC (2011) Non-homotheticity and bilateral trade: evidence and a quantitative explanation. Econometrica 79(4):1069-1101

Helpman E, Krugman P (1985) Market structure and international trade. MIT Press, Cambridge

Hottman CJ, Redding SJ, Weinstein DE (2016) Quantifying the sources of firm heterogeneity. Q J Econ 131(3):1291-1364

Jakel IC (2019) Product appeal, differences in tastes, and export performance: evidence for Danish chocolate and confectionery. Int J Ind Organ 63:417-459

Knight GA (1999) Consumer preferences for foreign and domestic products. J Consum Market 16(2):151-162

Krishna P, Mitra D (1998) Trade liberalization, market discipline and productivity growth: new evidence from India. J Dev Econ 56:447-462

Krugman PR (1980) Scale economies, product differentiation, and pattern of trade. Am Econ Rev 70(5):950-959

Levinsohn J (1993) Testing the imports-as-market-discipline hypothesis. J Int Econ 35(1-2):1-22

Lundin N (2004) Import Competition, Product Differentiation and Mark-Ups—Microeconomic evidence from Swedish manufacturing in the 1990s. FIEF Working Paper Series No. 195

Markusen JR (2013) Putting per-capita income back into trade theory. J Int Econ 90:255-265

Meinen P (2016) Markup responses to Chinese imports. Econ Lett 141:122-124

Noria GL (2013) The effect of trade liberalization on manufacturing price cost margins: the case of Mexico, 1994-2003. Banco de Mexico working paper No. 2013-10

Obstfeld M, Rogoff K (2000) The six major puzzles in international macroeconomics: is there a common cause? NBER Macroecon Annual 15:339-390

Simonovska I (2015) Income differences and prices of tradables. Rev Econ Stud 82(4):1612

Syverson C (2007) Prices, spatial competition and heterogeneous producers: an empirical test. J Ind Econ 55(2):197-222

Thompson AJ (2002) Import competition and market power: canadian evidence. N Am J Econ Finan 13:40-55

\section{Publisher's Note}

Springer Nature remains neutral with regard to jurisdictional claims in published maps and institutional affiliations. 